\title{
Air Pollutants, Climate, and the Prevalence of Pediatric Asthma in Urban Areas of China
}

\author{
Juanjuan Zhang, ${ }^{1}$ Jihong Dai, ${ }^{1,2}$ Li Yan, ${ }^{2}$ Wenlong Fu, ${ }^{2}$ Jing Yi, ${ }^{3}$ Yuzhi Chen, \\ Chuanhe Liu, ${ }^{4}$ Dongqun $X u,{ }^{5}$ and Qiang Wang ${ }^{5}$ \\ ${ }^{1}$ Center of Respiratory Disorders, Children's Hospital, Chongqing Medical University, Chongqing 400014, China \\ ${ }^{2}$ Ministry of Education Key Laboratory of Child Development and Disorders, Chongqing 400014, China \\ ${ }^{3}$ Department of Medical Statistics, Chongqing Medical University, Chongqing 400046, China \\ ${ }^{4}$ Center for Asthma Prevalence and Education, Capital Institute of Pediatrics, Beijing 100020, China \\ ${ }^{5}$ Institute of Environmental Health and Related Products Safety, Chinese Center for Disease Control and Prevention, \\ Beijing 100021, China
}

Correspondence should be addressed to Jihong Dai; dai.jihong@outlook.com

Received 20 April 2016; Revised 29 June 2016; Accepted 30 June 2016

Academic Editor: Taiyoun Rhim

Copyright (C) 2016 Juanjuan Zhang et al. This is an open access article distributed under the Creative Commons Attribution License, which permits unrestricted use, distribution, and reproduction in any medium, provided the original work is properly cited.

\begin{abstract}
Background. Prevalence of childhood asthma varies significantly among regions, while its reasons are not clear yet with only a few studies reporting relevant causes for this variation. Objective. To investigate the potential role of city-average levels of air pollutants and climatic factors in order to distinguish differences in asthma prevalence in China and explain their reasons. Methods. Data pertaining to 10,777 asthmatic patients were obtained from the third nationwide survey of childhood asthma in China's urban areas. Annual mean concentrations of air pollutants and other climatic factors were obtained for the same period from several government departments. Data analysis was implemented with descriptive statistics, Pearson correlation coefficient, and multiple regression analysis. Results. Pearson correlation analysis showed that the situation of childhood asthma was strongly linked with $\mathrm{SO}_{2}$, relative humidity, and hours of sunshine $(p<0.05)$. Multiple regression analysis indicated that, among the predictor variables in the final step, $\mathrm{SO}_{2}$ was found to be the most powerful predictor variable amongst all $(\beta=-19.572, p<0.05)$. Furthermore, results had shown that hours of sunshine $(\beta=-0.014, p<0.05)$ was a significant component summary predictor variable. Conclusion. The findings of this study do not suggest that air pollutants or climate, at least in terms of children, plays a major role in explaining regional differences in asthma prevalence in China.
\end{abstract}

\section{Introduction}

Asthma is one of the most chronic inflammatory disorders characterized by recurrent attacks of wheezing, breathlessness, cough, and/or chest tightness, which vary in severity and frequency from person to person. The prevalence of allergic airway diseases, such as asthma and rhinitis, has been increasingly common to epidemic proportions worldwide. About 334 million people worldwide are now suffering from asthma [1]. And China is one of the most asthma-afflicted countries, and its population of asthmatics is estimated to be approximately 30 million, including 10 million children [2].

And, more importantly, there are significantly striking differences in asthma symptoms worldwide [3,4]. The ISAAC
Phase Three has surveyed 800,000 children aged from 13 to 14 years in 233 collaborating centers in 98 countries and found that the prevalence of asthma symptoms ranged from $0.8 \%$ to $32.6 \%$ in countries $[4,5]$. And the Chinese National Cooperative Group on Children Asthma has conducted a sample survey from 1988 to 1990 [6] to assess the prevalence of asthma in children aged 0-14 years in China. In this survey, the reported prevalence of asthma (defined as having experienced an asthma attack in the past two years) ranged from 0.09 to $2.60 \%$, with an average of $0.91 \%$. In 2000 [6], after a 10-year interval, the same survey was conducted again. The preliminary findings indicated that the prevalence of asthma had increased to $0.52-3.34 \%$ in city-dwelling children, with the national average being 1.54\%. In 2010 [7], 
20 years after the original survey, the same methodology found that the prevalence of childhood asthma was estimated at $0.42-5.73 \%$, with the national average being $2.32 \%$. These results highlight two key conclusions: first, the number of pediatric asthma patients has risen over time; second, the prevalence of childhood asthma in China varies among regions.

A large number of studies have confirmed that respiratory diseases are related to the physical characteristics of the living area: asthma has multifactorial etiology, including exogenous factors like air pollution and climate. The link between urban air pollution, climatic factors, and asthma is stably established on the individual level. However, there are merely a few analyses developing a comparative approach of differences in asthma morbidity among places, such as cities. In addition, levels of outdoor air pollutants have been associated with asthma incidence but not clearly with asthma prevalence at the population level [8]. Under this circumstance, this paper investigated the regional disparities' correlation with air pollutants and climatic factors in different cities in China, with cities as the objects of the study. This is in contrast to many epidemiological study designs where information is available at the individual level. The result could offer novel insights into the impact of air pollutants and climate on asthma prevalence.

\section{Material and Methods}

2.1. Study Design and Criteria. The data of asthma, air pollutants, and other climatic factors were obtained from published journals or government departments. Asthma definition in this survey was based on the Global Initiative for Asthma, Chinese Guideline of Pediatric Asthma published in 2008 [9]. In the questionnaire, the primary inclusion criterion for asthma patients was a subject with definite wheezing three times and more. Stratified random sampling was to be adopted in this survey, and it was uniformly carried out by the Chinese National Cooperative Group on Children Asthma.

2.2. Asthma Data. Asthma data in this study were collected from the open-access Chinese Journal of Pediatrics [9]. The Chinese National Cooperative Group on Children Asthma organized the third nationwide survey of childhood asthma in urban areas of China, which included 463,982 children and identified 13,992 asthmatic patients aged $0-14$ years. The national survey was conducted in 43 cities across the country, and children's demographic characteristics were available. The selected data of asthma prevalence were defined as children who had experienced at least one asthma attack in the last two years (2009-2010), which contained 10,777 asthmatic patients. Data pertaining to the clinical and demographic characteristics of asthmatic patients in the 43 specific cities were not described as they were not made available by the third national survey.

Approval for the use of the data was obtained from the National Cooperative Group on Children Asthma. And informed consent was obtained from the next of kin, caretakers, or guardians on behalf of children. The consent on behalf of the children enrolled was written. The study design was approved by the ethics committee of the National Cooperative Group on Children Asthma.

2.3. Air Pollution Data. Air pollution data included the annual (from 2009 to 2010) average values for particulate matter less than or equal to $10 \mu \mathrm{m} \operatorname{PM} 10\left(\mu \mathrm{g} / \mathrm{m}^{3}\right)$, sulfur dioxide $\mathrm{SO}_{2}\left(\mu \mathrm{g} / \mathrm{m}^{3}\right)$, and nitrogen dioxide $\mathrm{NO}_{2}\left(\mu \mathrm{g} / \mathrm{m}^{3}\right)$. All the data were obtained from the State Statistical Bureau Network which collected annual average concentrations of air pollutants through automated fixed-site monitoring stations. The data were regularly recorded from January 1, 2009, to December 31, 2010. We collected and calculated the 2-year average (from 2009 to 2010) values of these variables, yet numbers of air quality monitoring stations in 43 cities were not available.

The World Health Organization Air Quality Guidelines for annual mean concentrations of PM10 and $\mathrm{NO}_{2}$ and for 24hour mean concentrations of $\mathrm{SO}_{2}$ were $20 \mu \mathrm{g} / \mathrm{m}^{3}, 40 \mu \mathrm{g} / \mathrm{m}^{3}$, and $20 \mu \mathrm{g} / \mathrm{m}^{3}$, respectively [10].

2.4. Meteorological Data. Meteorological data included the annual average values for temperatures $\left({ }^{\circ} \mathrm{C}\right)$, relative humidity (\%), precipitation ( $\mathrm{mm})$, and hours of sunshine (h). Obtained from the State Statistical Bureau Network and the China Meteorological Administration, these data were regularly recorded from January 1, 2009, to December 31, 2011, as well. We collected and calculated the 2-year averaged (from 2009 to 2010) value of these variables. The numbers of weather monitoring stations in 43 cities were also not available.

2.5. Statistical Methods. Descriptive statistics were used to summarize the general characteristics of the data included in this study. The Shapiro-Wilk test revealed a normal distribution of tested variables. The mean and standard deviation (SD) of each of the variables were then calculated. Associations were assessed with Pearson correlation coefficient and multiple regression analysis. Prevalence of asthma was the dependent variable, and independent variables were air pollutants ( $\mathrm{PM} 10, \mathrm{SO}_{2}$, and $\mathrm{NO}_{2}$ ) and climatic factors (relative humidity, air temperature, precipitation, and hours of sunshine). Statistical significance was set at $p<0.05$, and all statistical analyses were performed with SPSS software version 20.0 .

\section{Results}

3.1. Baseline Characteristics of Patients in the Third National Survey on Childhood Asthma. Table 1 shows the baseline characteristics of the patients from the third nationwide study of childhood asthma in urban areas of China [7].

The national prevalence of asthma in male and female children was $3.51 \%$ and $2.29 \%$, respectively. The prevalence of asthma was significantly higher in preschool children ( $n$ $=1,127,4.15 \%)$ than in school-age children $(n=8,429,2.82 \%)$ and infants $(n=4,026,1.77 \%)$. Within the total survey cohort, 12,997 (3.00\%) patients of Han descent, 87 (2.73\%) patients of Manchu descent, and 157 (2.39\%) patients of Hui descent 
TABLE 1: Demographic characteristics of the children surveyed in the 3rd national childhood asthma survey ${ }^{\mathrm{a}}$.

\begin{tabular}{|c|c|c|}
\hline & $\begin{array}{l}\text { Full survey } \\
(n, \text { total })\end{array}$ & $\begin{array}{l}\text { Asthmatic patients }(n[\% \text { of } \\
\text { full-survey population] })^{c}\end{array}$ \\
\hline Number of patients & 463,982 & $13,992(3.02 \%)$ \\
\hline \multicolumn{3}{|l|}{ Gender } \\
\hline Male & 241,811 & $8,495(3.51 \%)$ \\
\hline Female & 222,160 & $5,089(2.29 \%)$ \\
\hline \multicolumn{3}{|l|}{ Age } \\
\hline Infant ( $0-2$ years) & 63,717 & $1,127(1.77 \%)$ \\
\hline Preschool (3-5 years) & 97,075 & $4,026(4.15 \%)$ \\
\hline School age (6-14 years) & 303,245 & $8,429(2.82 \%)$ \\
\hline \multicolumn{3}{|l|}{ Race } \\
\hline Han & 433,951 & $12,997(3.00 \%)$ \\
\hline Manchus & 3,189 & $87(2.73 \%)$ \\
\hline Zhuang & 4,136 & $109(2.64 \%)$ \\
\hline Hui & 6,574 & $157(2.39 \%)$ \\
\hline Mongolian & 1,520 & $29(1.91 \%)$ \\
\hline Uygur & 1,781 & $14(0.79 \%)$ \\
\hline Tibetan & 4,346 & $22(0.51 \%)$ \\
\hline Inducing factors & & $\begin{array}{c}\text { (n [\% of total asthmatic } \\
\text { children]) }\end{array}$ \\
\hline Respiratory infection & - & $12,299(87.9 \%)$ \\
\hline Climate change & - & $7,204(51.5 \%)$ \\
\hline Exercise & - & $3,055(21.8 \%)$ \\
\hline Clinical features & - & \\
\hline Cough & - & $12,771(91.3 \%)$ \\
\hline Wheezing & - & $10,659(76.2 \%)$ \\
\hline \multicolumn{3}{|l|}{ Asthma attacks per year ${ }^{\mathrm{b}}$} \\
\hline $1-5$ & - & $10,682(87.7 \%)$ \\
\hline $6-10$ & - & $1,227(10.1 \%)$ \\
\hline$>10$ & - & $269(2.2 \%)$ \\
\hline \multicolumn{3}{|l|}{ Allergy history } \\
\hline Personal allergies & - & $10,143(72.5 \%)$ \\
\hline Allergic rhinitis & - & $7,010(50.1 \%)$ \\
\hline $\begin{array}{l}\text { Eczema/atopic } \\
\text { dermatitis }\end{array}$ & - & $4,147(29,6 \%)$ \\
\hline Urticaria & - & $2,683(19,2 \%)$ \\
\hline Food allergies & - & $2,079(14.9 \%)$ \\
\hline $\begin{array}{l}\text { Family history of } \\
\text { allergies }\end{array}$ & - & $6,321(45.2 \%)$ \\
\hline Family history of asthma & - & $2,924(20.9 \%)$ \\
\hline \multicolumn{3}{|l|}{ Therapy } \\
\hline Bronchodilators & - & $9,986(71.4 \%)$ \\
\hline Steroids & - & 8,209 (58.7\%) \\
\hline Leukotriene antagonist & - & $4,873(34.8 \%)$ \\
\hline Antiallergic agents & - & $6,352(45.4 \%)$ \\
\hline
\end{tabular}

TABLE 1: Continued.

\begin{tabular}{lcc}
\hline & $\begin{array}{c}\text { Full survey } \\
(n \text {, total })\end{array}$ & $\begin{array}{c}\text { Asthmatic patients }(n[\% \text { of } \\
\text { full-survey population] })^{c}\end{array}$ \\
\hline Antibiotics & - & $10,504(75.1 \%)$
\end{tabular}

(a) Data from the Chinese Journal of Pediatrics: third-nationwide survey of childhood asthma in urban areas of China, 2013.

(b) Data regarding the frequency of asthma attacks was only available for $12,178(87 \%)$ patients in the asthmatic cohort.

(c) Data pertaining to the prevalence, age, gender, and race of the asthmatic patients is presented as the percentage of the corresponding population in the full survey. For example, 3.51\% of all males surveyed met the criteria for an asthma diagnosis.

were asthmatic. In the asthmatic patients, respiratory tract infection $(n=12,299,87.9 \%)$ and changes in the weather conditions $(n=7,204,51.5 \%)$ were the most frequent triggers of asthma exacerbation. Common clinical manifestations of asthma were cough $(n=12,771,91.3 \%)$ and wheezing $(n=$ $10,659,76.2 \%)$. A family history of allergies was reported in $45.2 \%$ of patients $(n=6,321)$, and a personal history of allergies was reported in $72.5 \%$ of patients $(n=10,143)$. Regarding the frequency of asthma attacks each year, $87.7 \%$ of patients reported 1-5 asthma attacks, $10.1 \%$ reported 6-10 attacks, and only $2.2 \%$ reported more than 10 attacks. To treat asthmatic children, bronchodilators were used in $71.4 \%$ of cases $(n=9,986)$, inhaled corticosteroids in $58.7 \%(n=8,209)$, and antibiotics in $75.1 \%(n=10,504)$.

3.2. Asthma Prevalence, Air Pollutants, and Climatic Factors in 43 Cities. Table 2 is the summary of the prevalence of childhood asthma provided by the third national survey and the annual mean concentrations of air pollutants $\left(\mathrm{PM10}, \mathrm{SO}_{2}\right.$, and $\mathrm{NO}_{2}$ ), together with the annual mean levels of climatic factors (relative humidity, air temperature, precipitation, and hours of sunshine) for each of the 43 cities. There were statistically significant differences in asthma prevalence, air pollutants, and climatic factors between cities (Table 3). The most prevalent childhood asthma was found in Shanghai (5.73\%) and the least was in Lasa $(0.42 \%)$. The air index is listed as follows: the concentration of PM10 ranged from 0.024 to $0.153 \mathrm{mg} / \mathrm{m}^{3}$ and averaged $0.091 \mathrm{mg} / \mathrm{m}^{3}$, with a standard deviation of $0.026 \mathrm{mg} / \mathrm{m}^{3}$; the concentration of $\mathrm{SO}_{2}$ ranged from 0.007 to $0.091 \mathrm{mg} / \mathrm{m}^{3}$ and averaged $0.042 \mathrm{mg} / \mathrm{m}^{3}$, with a standard deviation of $0.018 \mathrm{mg} / \mathrm{m}^{3}$; the concentration of $\mathrm{NO}_{2}$ ranged from 0.016 to $0.160 \mathrm{mg} / \mathrm{m}^{3}$ and averaged $0.042 \mathrm{mg} / \mathrm{m}^{3}$, with a standard deviation of $0.015 \mathrm{mg} / \mathrm{m}^{3}$; relative humidity ranged from 32.000 to $81.000 \%$ and averaged $66.008 \%$, with a standard deviation of $10.366 \%$; the air temperatures over the course of the study ranged from 4.75 to $24.440^{\circ} \mathrm{C}$ and averaged $15.125^{\circ} \mathrm{C}$, with a standard deviation of $4.944^{\circ} \mathrm{C}$; precipitation ranged from 15.75 to $211.39 \mathrm{~mm}$ and averaged $82.92 \mathrm{~mm}$, with a standard deviation of $46.516 \mathrm{~mm}$; the duration of sunshine ranged from 67.880 to $265.810 \mathrm{~h}$ and averaged $166.08 \mathrm{~h}$, with a standard deviation of $43.524 \mathrm{~h}$ 
TABLE 2: Levels of childhood asthma prevalence, air pollutants, and climatic factors in Chinese cities.

\begin{tabular}{|c|c|c|c|c|c|c|c|c|}
\hline \multirow[b]{2}{*}{ City } & \multirow{2}{*}{$\begin{array}{l}\text { Asthma } \\
\text { prevalence } \\
(\%)\end{array}$} & \multicolumn{3}{|c|}{ Air pollutants } & \multicolumn{4}{|c|}{ Climatic factors } \\
\hline & & $\begin{array}{c}\mathrm{PM} 10 \\
\left(\mathrm{mg} / \mathrm{m}^{3}\right)\end{array}$ & $\begin{array}{c}\mathrm{SO}_{2} \\
\left(\mathrm{mg} / \mathrm{m}^{3}\right)\end{array}$ & $\begin{array}{c}\mathrm{NO}_{2} \\
\left(\mathrm{mg} / \mathrm{m}^{3}\right)\end{array}$ & $\begin{array}{c}\text { Relative } \\
\text { humidity (\%) }\end{array}$ & $\begin{array}{c}\text { Air } \\
\text { temperature } \\
\left({ }^{\circ} \mathrm{C}\right)\end{array}$ & $\begin{array}{l}\text { Precipitation } \\
\quad(\mathrm{mm})\end{array}$ & $\begin{array}{c}\text { Hours of } \\
\text { sunshine }(\mathrm{h})\end{array}$ \\
\hline Beijing & $344(2.55)$ & 0.121 & 0.033 & 0.055 & 51.0 & 12.93 & 41.80 & 203.95 \\
\hline Tianjin & $273(2.14)$ & 0.099 & 0.055 & 0.043 & 58.5 & 12.53 & 38.40 & 185.24 \\
\hline Shijiazhuang & $121(1.23)$ & 0.101 & 0.050 & 0.038 & 56.0 & 14.20 & 47.16 & 193.88 \\
\hline Taiyuan & $124(1.22)$ & 0.098 & 0.072 & 0.021 & 53.0 & 11.18 & 41.74 & 202.58 \\
\hline Baotou & $102(0.90)$ & 0.105 & 0.062 & 0.037 & 46.5 & 8.15 & 24.14 & 243.30 \\
\hline Shenyang & $148(1.62)$ & 0.106 & 0.059 & 0.036 & 69.0 & 7.47 & 70.60 & 205.64 \\
\hline Changchun & $187(1.56)$ & 0.087 & 0.032 & 0.044 & 63.0 & 5.63 & 56.64 & 196.35 \\
\hline Harbin & $109(1.03)$ & 0.101 & 0.046 & 0.051 & 67.5 & 4.75 & 46.89 & 181.71 \\
\hline Shanghai & $755(5.73)$ & 0.080 & 0.032 & 0.052 & 69.5 & 17.30 & 100.76 & 139.29 \\
\hline Nanjing & $206(1.60)$ & 0.107 & 0.036 & 0.047 & 71.5 & 16.31 & 110.91 & 156.77 \\
\hline Hangzhou & $496(3.57)$ & 0.098 & 0.038 & 0.054 & 71.5 & 17.60 & 132.58 & 141.63 \\
\hline Hefei & $483(5.18)$ & 0.113 & 0.022 & 0.029 & 72.5 & 16.57 & 94.53 & 152.51 \\
\hline Fuzhou & $479(4.08)$ & 0.069 & 0.012 & 0.036 & 72.0 & 20.53 & 124.13 & 128.80 \\
\hline Nanchang & $240(2.33)$ & 0.083 & 0.055 & 0.040 & 71.5 & 18.65 & 145.37 & 156.43 \\
\hline Jinan & $275(2.02)$ & 0.120 & 0.048 & 0.026 & 54.0 & 14.55 & 63.45 & 173.65 \\
\hline Zhengzhou & $329(3.19)$ & 0.105 & 0.053 & 0.046 & 58.5 & 15.55 & 56.78 & 149.75 \\
\hline Wuhan & $144(2.12)$ & 0.107 & 0.043 & 0.056 & 74.0 & 17.24 & 104.00 & 138.95 \\
\hline Changsha & $229(1.80)$ & 0.088 & 0.040 & 0.044 & 73.0 & 18.36 & 118.46 & 146.52 \\
\hline Guangzhou & $131(1.12)$ & 0.070 & 0.036 & 0.055 & 71.5 & 22.77 & 159.43 & 131.49 \\
\hline Nanning & $275(2.01)$ & 0.060 & 0.030 & 0.029 & 76.0 & 22.01 & 97.50 & 139.80 \\
\hline Haikou & $300(2.90)$ & 0.039 & 0.007 & 0.016 & 81.0 & 24.44 & 211.39 & 153.52 \\
\hline Chongqing & $424(3.64)$ & 0.104 & 0.051 & 0.038 & 79.0 & 18.82 & 93.48 & 77.27 \\
\hline Chengdu & $413(3.42)$ & 0.108 & 0.035 & 0.053 & 76.5 & 16.42 & 69.21 & 67.88 \\
\hline Guiyang & $146(1.38)$ & 0.075 & 0.058 & 0.027 & 75.5 & 14.77 & 77.48 & 81.50 \\
\hline Kunming & $104(0.97)$ & 0.070 & 0.041 & 0.046 & 66.0 & 16.63 & 59.79 & 181.16 \\
\hline Lhasa & $21(0.42)$ & 0.049 & 0.008 & 0.021 & 32.0 & 10.14 & 29.33 & 265.81 \\
\hline Xi'an & $219(1.83)$ & 0.120 & 0.046 & 0.046 & 63.0 & 14.83 & 44.57 & 147.91 \\
\hline Lanzhou & $253(2.39)$ & 0.153 & 0.058 & 0.046 & 54.5 & 7.95 & 15.75 & 209.50 \\
\hline Xining & $62(1.01)$ & 0.133 & 0.041 & 0.029 & 56.5 & 6.28 & 36.00 & 218.45 \\
\hline Yinchuan & $29(0.66)$ & 0.092 & 0.042 & 0.029 & 49.5 & 10.38 & 16.10 & 232.91 \\
\hline Urumqi & $121(1.01)$ & 0.137 & 0.091 & 0.068 & 56.0 & 7.70 & 26.48 & 235.45 \\
\hline Baoji & $467(4.36)$ & 0.024 & 0.028 & 0.106 & 63.0 & 14.05 & 61.97 & 137.53 \\
\hline Yuxi & $96(0.59)$ & 0.082 & 0.059 & 0.022 & 76.0 & 17.15 & 52.83 & 201.37 \\
\hline Yichang & $286(2.72)$ & 0.086 & 0.046 & 0.025 & 75.5 & 17.35 & 105.99 & 101.83 \\
\hline Shenzhen & 117 (1.63) & 0.057 & 0.012 & 0.044 & 71.5 & 23.10 & 135.21 & 156.79 \\
\hline Zhongshan & $139(1.34)$ & 0.052 & 0.029 & 0.040 & 79.0 & 22.60 & 165.94 & 153.77 \\
\hline Qingdao & $337(3.35)$ & 0.099 & 0.052 & 0.046 & 63.8 & 13.00 & 57.47 & 183.21 \\
\hline Yantai & $623(4.74)$ & 0.082 & 0.043 & 0.040 & 67.5 & 12.40 & 59.45 & 204.75 \\
\hline Linyi & $60(0.60)$ & 0.112 & 0.082 & 0.049 & 63.6 & 13.84 & 58.01 & 185.46 \\
\hline Suzhou & $352(3.22)$ & 0.090 & 0.034 & 0.052 & 69.0 & 17.20 & 89.10 & 149.67 \\
\hline Anqing & $272(2.97)$ & 0.086 & 0.053 & 0.038 & 72.5 & 17.25 & 130.68 & 136.30 \\
\hline Wenzhou & $250(2.54)$ & 0.081 & 0.028 & 0.056 & 73.5 & 18.70 & 163.53 & 126.50 \\
\hline Xiamen & $236(2.13)$ & 0.063 & 0.021 & 0.043 & 74.0 & 21.10 & 130.70 & 164.96 \\
\hline
\end{tabular}

Note. PM10: particulates with an aerodynamic diameter of $10 \mathrm{~mm} ; \mathrm{SO}_{2}$ : sulfur dioxide; $\mathrm{NO}_{2}$ : nitrogen dioxide. 
TABLE 3: Descriptive statistical analysis of the variables.

\begin{tabular}{|c|c|c|c|c|c|}
\hline Variables & $N$ & Minimum & Maximum & Mean & Std. deviation \\
\hline Asthma prevalence & 43 & 0.420 & 5.730 & 2.252 & 1.297 \\
\hline PM10 & 43 & 0.024 & 0.153 & 0.091 & 0.026 \\
\hline $\mathrm{SO}_{2}$ & 43 & 0.007 & 0.091 & 0.042 & 0.018 \\
\hline $\mathrm{NO}_{2}$ & 43 & 0.016 & 0.106 & 0.042 & 0.015 \\
\hline Relative humidity & 43 & 32.000 & 81.000 & 66.008 & 10.366 \\
\hline Air temperature & 43 & 4.750 & 24.440 & 15.125 & 4.994 \\
\hline Precipitation & 43 & 15.750 & 211.390 & 82.924 & 46.516 \\
\hline Hours of sunshine & 43 & 67.880 & 265.810 & 166.087 & 43.524 \\
\hline
\end{tabular}

Note. PM10: particulates with an aerodynamic diameter of $10 \mathrm{~mm} ; \mathrm{SO}_{2}$ : sulfur dioxide; $\mathrm{NO}_{2}$ : nitrogen dioxide.

TABLE 4: The relationships among air pollutants, climatic factors, and asthma prevalence by Pearson correlation coefficient.

\begin{tabular}{|c|c|c|c|c|c|c|c|c|}
\hline Variables & $\begin{array}{c}\text { Asthma } \\
\text { prevalence }\end{array}$ & PM10 & $\mathrm{SO}_{2}$ & $\mathrm{NO}_{2}$ & $\begin{array}{l}\text { Relative } \\
\text { humidity }\end{array}$ & $\begin{array}{c}\text { Air } \\
\text { temperature }\end{array}$ & Precipitation & $\begin{array}{l}\text { Hours of } \\
\text { sunshine }\end{array}$ \\
\hline Asthma prevalence & 1 & -0.101 & $-0.323^{*}$ & 0.261 & $0.351^{*}$ & 0.289 & 0.273 & $-0.476^{* *}$ \\
\hline PM10 & & 1 & $0.607^{* *}$ & -0.023 & $-0.308^{*}$ & $-0.551^{* *}$ & $-0.529^{* *}$ & 0.231 \\
\hline $\mathrm{SO}_{2}$ & & & 1 & 0.050 & -0.213 & $-0.480^{* *}$ & $-0.500^{* *}$ & 0.225 \\
\hline $\mathrm{NO}_{2}$ & & & & 1 & 0.029 & -0.061 & -0.037 & -0.157 \\
\hline Relative humidity & & & & & 1 & $0.668^{* *}$ & $0.740^{* *}$ & $-0.771^{* *}$ \\
\hline Airtemperature & & & & & & 1 & $0.821^{* *}$ & $-0.635^{* *}$ \\
\hline Precipitation & & & & & & & 1 & $-0.577^{* *}$ \\
\hline Hours of sunshine & & & & & & & & 1 \\
\hline
\end{tabular}

Note. PM10: particulates with an aerodynamic diameter of $10 \mathrm{~mm} ; \mathrm{SO}_{2}$ : sulfur dioxide; $\mathrm{NO}_{2}$ : nitrogen dioxide. ${ }^{*} p<0.05 .{ }^{* *} p<0.01$.

3.3. Correlations between Asthma Prevalence, Air Pollutants, and Climatic Factors in 43 Cities. The results of the Pearson correlation coefficient and multiple regression analysis describing the relationship between asthma prevalence and risk factors (air pollutants and climatic factors) are shown in Tables 4 and 5. According to Pearson correlation analysis (Table 4), there were significant associations between asthma prevalence and several factors including $\mathrm{SO}_{2}(r=-0.323, p<$ $0.05)$, relative humidity $(r=-0.351, p<0.05)$, and hours of sunshine $(r=-0.476, p<0.05)$. As can be seen, these correlations between $\mathrm{PM} 10, \mathrm{NO}_{2}$, air temperature, precipitation, and asthma prevalence were not statistically significant. Therefore, the multiple linear regression analysis with a dependent variable of asthma prevalence and independent variables of $\mathrm{SO}_{2}$, relative humidity, and hours of sunshine was used to predict asthma prevalence. The prediction model was statistically significant $(F=5.573, p<0.01)$ and accounted for approximately $30.3 \%$ of the variance of asthma prevalence $\left(R=0.608\right.$, adjusted $\left.R^{2}=0.370\right)$. Multiple regression analysis indicated that, among the predictor variables, $\mathrm{SO}_{2}$ was found to be the most powerful predictor variable amongst all $(\beta=$ $-19.572, p<0.05)$. Furthermore, results had shown that hours of sunshine $(\beta=-0.014, p<0.05)$ was a significant component summary predictor variable. However, relative humidity was not significantly predicted to be the outcome measure.

\section{Discussion}

The aim of this study was to investigate the potential role of city-average air-pollutant levels and climatic factors in explaining regional differences in asthma prevalence in China. Variables for significant correlation coefficients were also obtained in the multiple regression analysis. They were the mean $\mathrm{SO}_{2}$ and hours of sunshine. Before the discussion of the findings, it is important to address methodological aspects of this study. This paper does not focus on the individuals themselves but cities, which is in contrast to many epidemiological study designs where information is available at the individual level. In addition, our data was available at annual mean level rather than daily. The size of the study was large, and although large-scale researches were accomplished by ISAAC in reference to asthma for air pollution $[5,11]$ and climate $[5,12]$, their 43 cities in China made for acceptable discrimination.

A growing body of research on time trends is devoted to the relationship between allergic respiratory diseases including asthma and environmental factors, climate conditions and air pollutants, but results on effects of these variables on asthma are still unclear and current knowledge is provided by epidemiological and experimental studies.

The adverse effect of air pollution on respiratory health has been well established in the literature $[13,14]$, but our results are not consistent with this evidence. The concentration of pollutants such as PM10 and $\mathrm{NO}_{2}$ no longer provides a statistical explanation for variations in asthma prevalence across urban units. Interestingly, the relationship between childhood asthma and $\mathrm{SO}_{2}$ was consistently negative. And surprisingly, these annual mean levels of PM10 $\left(0.091 \mathrm{mg} / \mathrm{m}^{3}\right), \mathrm{NO}_{2}\left(0.042 \mathrm{mg} / \mathrm{m}^{3}\right)$, and $\mathrm{SO}_{2}\left(0.042 \mathrm{mg} / \mathrm{m}^{3}\right)$ detected during the sampling period did not conform with 
TABLE 5: Multiple linear regression analysis of risk factors and asthma prevalence in children.

\begin{tabular}{lcccccr}
\hline \multirow{2}{*}{ Model } & \multicolumn{2}{c}{ Unstandardized coefficients } & Standardized coefficients & $t$ & Sig. & \multicolumn{2}{c}{ Collinearity statistics } \\
& $\mathrm{B}$ & Std. error & Beta & & & Tolerance \\
\hline Constant & 1.673 & 3.104 & & 0.539 & 0.593 & \\
$\mathrm{SO}_{2}$ & -19.572 & 9.654 & -0.271 & -2.027 & 0.050 & 0.930 \\
Relative humidity & -0.036 & 0.028 & -0.291 & -1.294 & 0.204 & 0.329 \\
Hours of sunshine & -0.014 & 0.006 & -0.458 & -2.256 & 0.030 & 0.402 \\
\hline
\end{tabular}

Note. PM10: particulates with an aerodynamic diameter of $10 \mathrm{~mm} ; \mathrm{SO}_{2}$ : sulfur dioxide; predictors: $\mathrm{SO}_{2}$, relative humidity, and hours of sunshine; dependent variable: asthma prevalence; $R^{2}=$ squared multiple correlation of $y$ with $x \cdot R^{2}=0.303, F=5.573$, and $p<0.01$.

the data from World Health Organization Air Quality Guidelines [10]. This result is consistent with previous intercommunity studies $[10,15-18]$, including ones of the ISAAC $[5,15,16]$ which did not observe positive associations between ambient air pollutants and asthma prevalence. However, a study of individual level by ISAAC found a positive association between asthma prevalence and proximity to traffic pollution [19]. The disparities between these findings and those of within-community studies of individuals exposed to air pollutants remain to be further explained. This is compatible with the hypothesis that outdoor levels of air pollutants have been associated with asthma incidence but not with asthma prevalence at the population level.

The influence of short-term climate change on asthma exacerbation is well established, but its long-term influence on disease occurrence is little studied.

Regarding the effect of climatic variables, a large number of studies have confirmed that temperature is related to asthma [12, 20-31]. However, for our study, there has not been shown any statistically significant association between annual mean temperature and asthma prevalence, which are similar to some established in extraurban studies $[12,22]$. Our results are different, because asthma prevalence was the object of study and not asthma incidence or asthma symptoms in the literature $[12,21,25]$, and climatic parameters considered in the literature vary: annual mean minimum or maximum temperature [23], annual mean or seasonal mean temperature $[12,21,26,27]$, mean temperature for the coldest or hottest months [22], daily temperature [1, 17, 24, 25], and monthly temperature [28-31]. Thus, a direct comparison of results is not possible.

In the present study, annual mean relative humidity was not related to asthma prevalence. Indeed, relative humidity has been associated with the prevalence of wheezing [26, 29], symptoms, diagnosis, and incidence of asthma $[5,24$, $26-28,32,33]$. But a few studies failed to show significant associations $[12,30,31]$, most likely due to different parameters. As mentioned above, our data were available on annual mean relative humidity, not including minimum or maximum relative humidity and other parameters. And our results indicate that hours of sunshine is a protective factor with the prevalence of asthma in the cities studied, which is consistent with results reported by recent epidemiological studies [11, 28-30, 34]. In addition, a recent analysis of ISAAC data supports the argument that there exists a negative relationship between the prevalence of asthma and the mean annual sunny hours at a community level within centers [35]. Indirectly, the results could support the hypothesis of the protective effect of vitamin $\mathrm{D}$ in the prevalence of asthma in children [35].

These few studies analyzing associations of asthma with precipitation $[28,30,31,36]$ showed mixed results. There is no confirmation in the literature that the association between climate and asthma prevalence reflects a causal relationship or that correlations are a result of indirect relationships and linked to other factors like air pollution levels. Little is known about the long-term influence of climate on asthma prevalence, but the findings from our study do not suggest that climate, at least in children, plays a major role.

The reasons for the inconsistencies among our study and previous studies are possibly regional discrepancies such as geographical environment, economic development, and density of the local populations. Additionally, study design, analyzing method, subgroups of children, and different parameters may also contribute to the controversies. Thus, a direct comparison of results is not accurate.

On the other hand, there are still several limitations in this study. First, modeled estimates of air pollutants and climatic factors at city level are imprecise and incomplete in terms of personal exposure to ambient air pollutants. Second, collinearity between variables and the time series impeded the evaluation of particular pollutants or climatic factors that had a direct adverse effect on the prevalence of asthma. Third, other factors such as the indoor environment [37], economic development [38, 39], dietary factors [40], pollen levels [41], and infections [42], which were not accounted for in our analysis, could have precipitated the regional differences in asthma prevalence. Fourth, our data were given on annual basis rather than monthly or daily. Under this circumstance, any short-term effect of short duration weather and air pollution changes could be lost, but not of changes for longer duration. Fifth, there might be subjects who were not new onset asthmatic patients. Therefore the two-year data could not precisely reflect the relationship between these factors and asthma prevalence. Finally, the data from the third national survey did not provide the clinical and demographic characteristics of the asthmatic patients in the specific cities and the precise time of asthma prevalence we used for our analyses. The limited access to this information hindered our pace to dig in the relationship between climatic and air quality factors and the clinical presentation of asthma in each city. 


\section{Conclusion}

To conclude, our study showed associations between longterm exposure to urban air pollution and climate conditions, using Pearson correlation coefficient and multiple regression analysis capturing variations within communities, and asthma. First, the study shows the surprising results for the contribution of pollution factors. In contrast to reports from within-community studies of individuals exposed to traffic pollution, we found no evidence of a positive relation between air pollution and asthma prevalence. Meanwhile, our results suggest that climate may affect the prevalence of asthma, yet climate does not play a major role, at least in terms of children.

\section{Disclosure}

The funders had no role in study design, data collection and analysis, decision to publish, or preparation of the paper.

\section{Competing Interests}

The authors declare that they have no competing interests.

\section{Authors' Contributions}

The work distribution of this paper is as follows. Juanjuan Zhang and Jihong Dai conceived and designed the study. Juanjuan Zhang conducted the data analyses and prepared the paper. Jihong Dai, Li Yan, and Wenlong Fu reviewed and edited the paper. Jing Yi put forward some important suggestions and comments on statistics. Yuzhi Chen, Chuanhe Liu, Dongqun $\mathrm{Xu}$, and Qiang Wang contributed to the materials of the study. And the paper was read and approved by all authors.

\section{Acknowledgments}

The study was supported by the Chongqing Medical Scientific Research Projects (Grant no. 20141008) and the Guizhou Science and Technology Fund Project (Grant no. 20152154). The authors would like to express their gratitude to all the professors in the National Cooperative Group on Children Asthma, for their devotion to the nationwide survey of childhood asthma in urban areas of China. Yuzhi Chen, Chuanhe Liu, Dongqun $\mathrm{Xu}$, and Qiang Wang are members of the Chinese National Cooperative Group on Children Asthma. The authors would also like to acknowledge Jianan Dai and Zhanglu Wang for their suggestions and comments on statistics. The authors also thank Medjaden Bioscience Limited for editing in the preparation of this paper.

\section{References}

[1] I. Asher and N. Pearce, "Global burden of asthma among children," International Journal of Tuberculosis and Lung Disease, vol. 18, no. 11, pp. 1269-1278, 2014.

[2] Z.-H. Chen, P.-L. Wang, and H.-H. Shen, "Asthma research in China: a five-year review," Respirology, vol. 18, supplement 3, pp. 10-19, 2013.
[3] M. I. Asher, R. Beasley, T. O. Clayton, and A. W. Stewart, "Worldwide variations in the prevalence of asthma symptoms: the International Study of Asthma and Allergies in Childhood (ISAAC)," European Respiratory Journal, vol. 12, no. 2, pp. 315335, 1998.

[4] C. K. W. Lai, R. Beasley, J. Crane et al., "Global variation in the prevalence and severity of asthma symptoms: phase Three of the International Study of Asthma and Allergies in Childhood (ISAAC)," Thorax, vol. 64, no. 6, pp. 476-483, 2009.

[5] J. Mallol, J. Crane, E. von Mutius, J. Odhiambo, U. Keil, and A. Stewart, "The International Study of Asthma and Allergies in Childhood (ISAAC) Phase Three: a global synthesis," Allergologia et Immunopathologia, vol. 41, no. 2, pp. 73-85, 2013.

[6] Y.-Z. Chen, "Comparative analysis of the state of asthma prevalence in children from two nation-wide surveys in 1990 and 2000 year," Zhonghua Jie He He Hu Xi Za Zhi, vol. 27, no. 2, pp. 112-116, 2004.

[7] National Cooperative Group on Childhood Asthma, Institute of Environmental Health and Related Product Safety, and Chinese Center for Disease Control and Prevention, "Third nationwide survey of childhood asthma in urban areas of China," Zhonghua Er Ke Za Zhi, vol. 51, no. 10, pp. 729-735, 2013.

[8] G. D’Amato, S. T. Holgate, R. Pawankar et al., "Meteorological conditions, climate change, new emerging factors, and asthma and related allergic disorders. A statement of the World Allergy Organization," World Allergy Organization Journal, vol. 8, no. 1, article 25, 2015.

[9] Subspecialty Group of Respiratory Diseases, The Society of Pediatrics, Chinese Medical Association, Editorial Board, and Chinese Journal of Pediatrics, "Guideline for the diagnosis and optimal management of asthma in children," Zhonghua Er Ke Za Zhi, vol. 46, no. 10, pp. 745-753, 2008.

[10] Europe WHOROf and WHO, Air Quality Guidelines: Global Update 2005: Particulate Matter, Ozone, Nitrogen Dioxide, and Sulfur Dioxide, World Health Organization, Geneva, Switzerland, 2006.

[11] S. Yamazaki, M. Shima, Y. Yoda et al., "Association of ambient air pollution and meteorological factors with primary care visits at night due to asthma attack," Environmental Health and Preventive Medicine, vol. 18, no. 5, pp. 401-406, 2013.

[12] S. K. Weiland, A. Hüsing, D. P. Strachan, P. Rzehak, and N. Pearce, "Climate and the prevalence of symptoms of asthma, allergic rhinitis, and atopic eczema in children," Occupational and Environmental Medicine, vol. 61, no. 7, pp. 609-615, 2004.

[13] F. C. Goldizen, P. D. Sly, and L. D. Knibbs, "Respiratory effects of air pollution on children," Pediatric Pulmonology, vol. 51, no. 1, pp. 94-108, 2016.

[14] J. Gasana, D. Dillikar, A. Mendy, E. Forno, and E. Ramos Vieira, "Motor vehicle air pollution and asthma in children: a metaanalysis," Environmental Research, vol. 117, pp. 36-45, 2012.

[15] H. R. Ross Anderson, B. K. Butland, A. van Donkelaar et al., "Satellite-based estimates of ambient air pollution and global variations in childhood asthma prevalence," Environmental Health Perspectives, vol. 120, no. 9, pp. 1333-1339, 2012.

[16] H. R. Anderson, R. Ruggles, K. D. Pandey et al., "Ambient particulate pollution and the world-wide prevalence of asthma, rhinoconjunctivitis and eczema in children: phase one of the International Study of Asthma and Allergies in Childhood (ISAAC)," Occupational and Environmental Medicine, vol. 67, no. 5, pp. 293-300, 2010.

[17] H. R. Anderson, G. Favarato, and R. W. Atkinson, "Longterm exposure to outdoor air pollution and the prevalence of 
asthma: meta-analysis of multi-community prevalence studies," Air Quality, Atmosphere \& Health, vol. 6, no. 1, pp. 57-68, 2013.

[18] WHO, Effects of Air Pollution on Children's Health and Development: A Review of the Evidence, WHO, Geneva, Switzerland, 2005.

[19] B. Brunekreef, A. W. Stewart, H. Ross Anderson, C. K. W. Lai, D. P. Strachan, and N. Pearce, "Self-reported truck traffic on the street of residence and symptoms of asthma and allergic disease: a global relationship in ISAAC phase 3," Environmental Health Perspectives, vol. 117, no. 11, pp. 1791-1798, 2009.

[20] S. Hales, S. Lewis, T. Slater, J. Crane, and N. Pearce, "Prevalence of adult asthma symptoms in relation to climate in New Zealand," Environmental Health Perspectives, vol. 106, no. 9, pp. 607-610, 1998.

[21] R. de Marco, A. Poli, M. Ferrari et al., "The impact of climate and traffic-related $\mathrm{NO}_{2}$ on the prevalence of asthma and allergic rhinitis in Italy," Clinical and Experimental Allergy, vol. 32, no. 10, pp. 1405-1412, 2002.

[22] G. Verlato, R. Calabrese, and R. De Marco, "Correlation between asthma and climate in the European community respiratory health survey," Archives of Environmental Health, vol. 57, no. 1, pp. 48-52, 2002.

[23] M. E. Zanolin, C. Pattaro, A. Corsico et al., "The role of climate on the geographic variability of asthma, allergic rhinitis and respiratory symptoms: results from the Italian study of asthma in young adults," Allergy, vol. 59, no. 3, pp. 306-314, 2004.

[24] N. Mireku, Y. Wang, J. Ager, R. C. Reddy, and A. P. Baptist, "Changes in weather and the effects on pediatric asthma exacerbations," Annals of Allergy, Asthma and Immunology, vol. 103, no. 3, pp. 220-224, 2009.

[25] Y. Zhang, L. Peng, H. Kan et al., "Effects of meteorological factors on daily hospital admissions for asthma in adults: a timeseries analysis," PLoS ONE, vol. 9, no. 7, article e102475, 2014.

[26] E. Kurt, S. Metintas, I. Basyigit et al., "Prevalence and risk factors of allergies in Turkey: results of a multicentric cross-sectional study in children," Pediatric Allergy and Immunology, vol. 18, no. 7, pp. 566-574, 2007.

[27] Y. L. Guo, Y.-C. Lin, F.-C. Sung et al., "Climate, traffic-related air pollutants, and asthma prevalence in middle-school children in Taiwan," Environmental Health Perspectives, vol. 107, no. 12, pp. 1001-1006, 1999.

[28] S. Xirasagar, H.-C. Lin, and T.-C. Liu, "Seasonality in pediatric asthma admissions: the role of climate and environmental factors," European Journal of Pediatrics, vol. 165, no. 11, pp. 747752, 2006.

[29] P. T. Nastos, A. G. Paliatsos, M. Papadopoulos, C. Bakoula, and K. N. Priftis, "The effect of weather variability on pediatric asthma admissions in Athens, Greece," Journal of Asthma, vol. 45 , no. 1 , pp. $59-65,2008$.

[30] C.-H. Chen, S. Xirasagar, and H.-C. Lin, "Seasonality in adult asthma admissions, air pollutant levels, and climate: A Population-Based Study," Journal of Asthma, vol. 43, no. 4, pp. 287-292, 2006.

[31] M. A. Tosca, S. Ruffoni, G. W. Canonica, and G. Ciprandi, "Asthma exacerbation in children: relationship among pollens, weather, and air pollution," Allergologia et Immunopathologia, vol. 42, no. 4, pp. 362-368, 2014.

[32] K. N. Priftis, A. G. Paliatsos, P. Panagiotopoulou-Gartagani et al., "Association of weather conditions with childhood admissions for wheezy bronchitis or asthma in Athens," Respiration, vol. 73, no. 6, pp. 783-790, 2006.
[33] L. García-Marcos, J. Batllés-Garrido, A. Blanco-Quirós et al., "Influence of two different geo-climatic zones on the prevalence and time trends of asthma symptoms among Spanish adolescents and schoolchildren," International Journal of Biometeorology, vol. 53, no. 1, pp. 53-60, 2009.

[34] S. Yamazaki, M. Shima, Y. Yoda et al., "Exposure to air pollution and meteorological factors associated with children's primary care visits at night due to asthma attack: case-crossover design for 3-year pooled patients," BMJ Open, vol. 5, no. 4, Article ID e005736, 2015.

[35] A. Arnedo-Pena, L. García-Marcos, J. F. Fernández-Espinar et al., "Sunny hours and variations in the prevalence of asthma in schoolchildren according to the International Study of Asthma and Allergies (ISAAC) Phase III in Spain," International Journal of Biometeorology, vol. 55, no. 3, pp. 423-434, 2011.

[36] M. Akpinar-Elci, F. E. Martin, J. G. Behr, and R. Diaz, "Saharan dust, climate variability, and asthma in Grenada, the Caribbean," International Journal of Biometeorology, vol. 59, no. 11, pp. 1667-1671, 2015.

[37] S. K. Ahluwalia and E. C. Matsui, "The indoor environment and its effects on childhood asthma," Current Opinion in Allergy and Clinical Immunology, vol. 11, no. 2, pp. 137-143, 2011.

[38] A. L. Kozyrskyj, G. E. Kendall, P. Jacoby, P. D. Sly, and S. R. Zubrick, "Association between socioeconomic status and the development of asthma: analyses of income trajectories," American Journal of Public Health, vol. 100, no. 3, pp. 540-546, 2010.

[39] A. W. Stewart, E. A. Mitchell, N. Pearce, D. P. Strachan, and S. K. Weiland, "The relationship of per capita gross national product to the prevalence of symptoms of asthma and other atopic diseases in children (ISAAC)," International Journal of Epidemiology, vol. 30, no. 1, pp. 173-179, 2001.

[40] R. Barros, A. Moreira, P. Padrão et al., "Dietary patterns and asthma prevalence, incidence and control," Clinical and Experimental Allergy, vol. 45, no. 11, pp. 1673-1680, 2015.

[41] K. Meister and B. Forsberg, "Short-term effects of airborne pollen on emergency department visits for asthma in three Swedish cities," European Respiratory Journal, vol. 44, supplement 58, p. P1954, 2014.

[42] V. Patella, M. Bocchino, and G. Steinhilber, "Asthma is associated with increased susceptibility to infection," Minerva Medica, vol. 106, no. 4, supplement 3, pp. 1-7, 2015. 


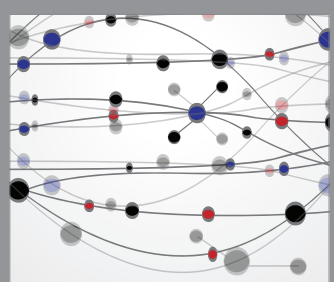

The Scientific World Journal
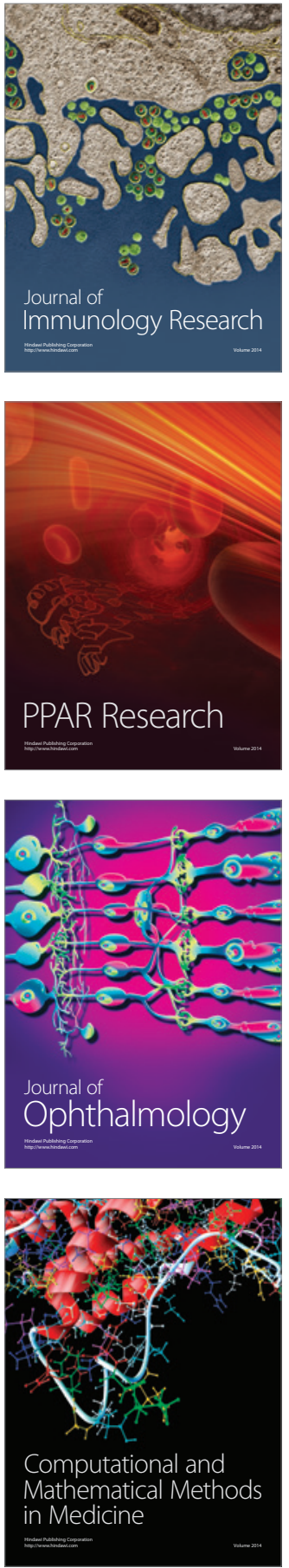

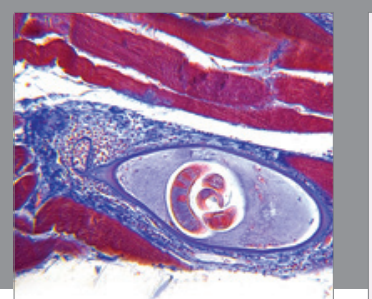

Gastroenterology Research and Practice

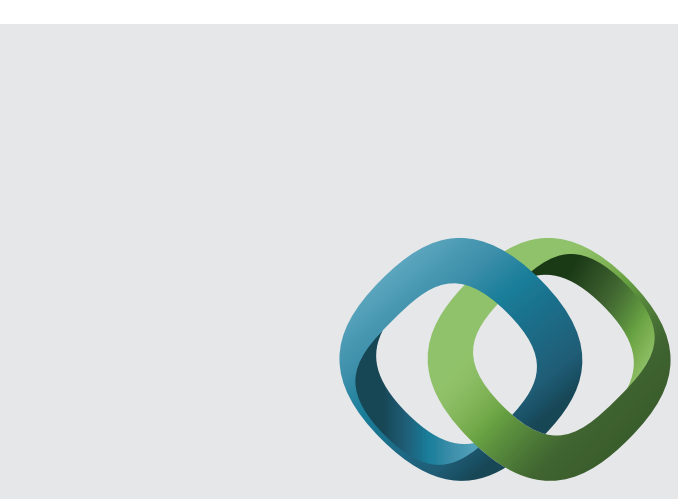

\section{Hindawi}

Submit your manuscripts at

http://www.hindawi.com
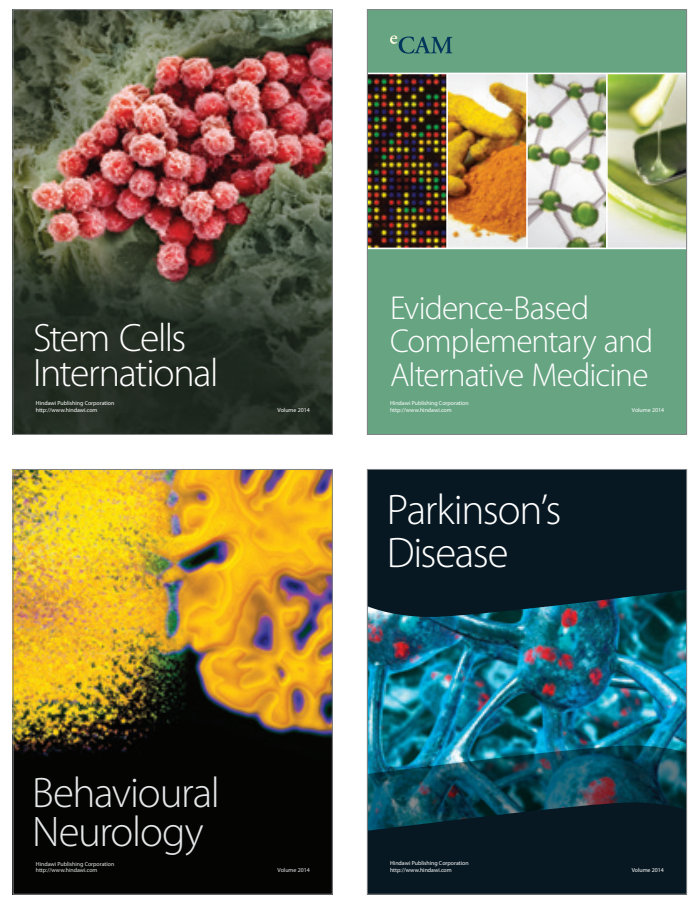
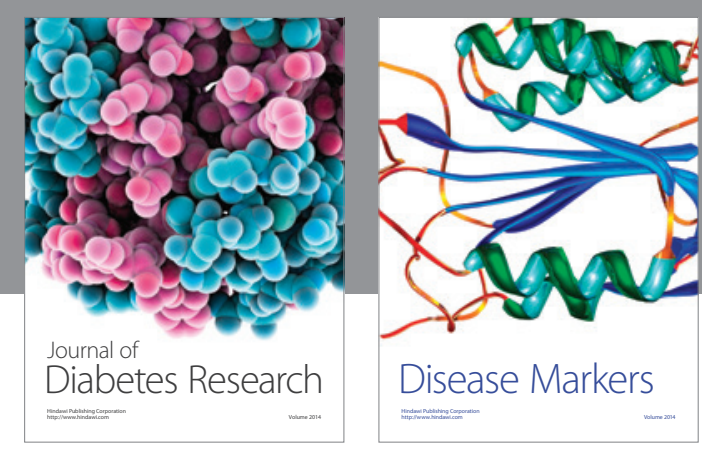

Disease Markers
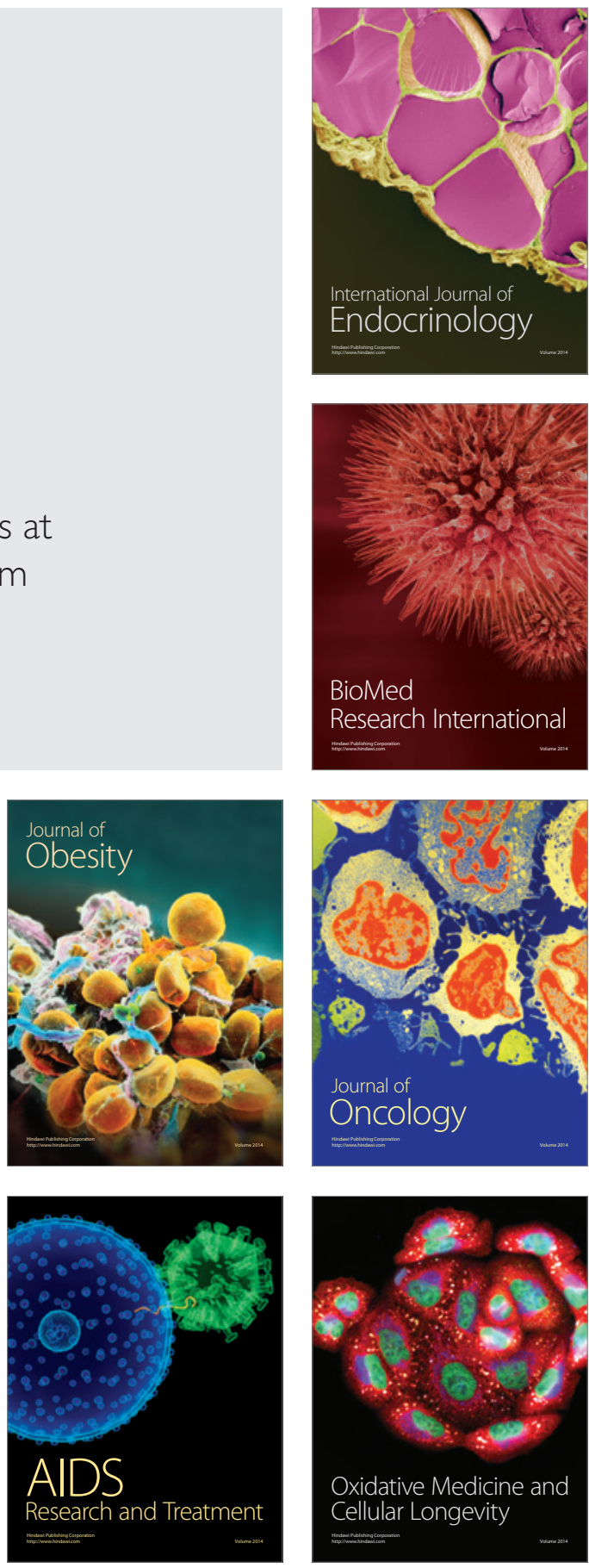